\title{
The Heart of the Matter. About Good Nursing and Telecare
}

\author{
Jeannette Pols
}

Published online: 10 January 2010

(C) The Author(s) 2009. This article is published with open access at Springerlink.com

\begin{abstract}
Nurses and ethicists worry that the implementation of care at a distance or telecare will impoverish patient care by taking out 'the heart' of the clinical work. This means that telecare is feared to induce the neglect of patients, and to possibly hinder the development of a personal relation between nurse and patient. This study aims to analyse whether these worries are warranted by analysing Dutch care practices using telemonitoring in care for chronic patients in the Netherlands. How do clinical practices of nursing change when telecare devices are introduced and what this means for notions and norms of good nursing? The paper concludes that at this point the practices studied do not warrant the fear of negligence and compromised relations. Quite the contrary; in the practices studied, telecare lead to more frequent and more specialised contacts between nurses and patients. The paper concludes by reflecting on the ethical implications of these changes.
\end{abstract}

Keywords Good nursing - Empirical ethics - Telecare - Clinical practice . Health care technology $\cdot$ Ethnography

\section{Introduction}

Homecare nurse on a conference on telecare: I think, as a nurse you have a kind of 6th sense. When you visit patients at home, you immediately sense when something is wrong. It is very hard to put into words, but it is pivotal for your work. If you use a webcam, you wouldn't, for instance, be able to smell the dishes that are there for a long time. What happens if you take that away?

\footnotetext{
J. Pols (ه)

Department of General Practice, Section of Medical Ethics, Academic Medical Centre (AMC) Amsterdam, Postbox 22700, 1100 DE Amsterdam, The Netherlands e-mail: a.j.pols@amc.uva.nl
} 
Wouldn't you destroy the heart of what it means to be a nurse? That is what I am worried about.

Telecare is described as care where care receiver and carer are at a distance from each other. ${ }^{1}$ The above quote comes from the notes I took on a European conference on telecare that was organised in the Netherlands in September 2007. ${ }^{2}$ The conference was set up to discuss worries and opportunities for telecare in the care for elderly people. The remark from the nurse is exemplary for the kind of worries that can be heard more widely in discussions about telecare. The professional fear is that the use of telecare systems will make it more difficult for nurses to act competently and responsibly when looking after patients, particularly because care is at a distance and the nurse is not physically present [28, 30]. Although videoconferencing often has a better press [5, 15, 23], monitoring devices not involving eye to eye contact are regarded with suspicion. The horror images seem to be negligence and coldness: the patient is 'on telecare', but gets worse, without anybody having noticed it $[2,11,16]$. In the end the image is that the patient sadly dies alone, if under the rational surveillance of electronic movement detectors, without a warm human hand on his or her shoulder (see for a discussion between warm care and cold technologies: [20]). Because with telecare it is not possible to use all senses, let alone a sixth, the nurses worry about missing signs of trouble and losing 'human interest', both of which are thought of as forming the heart of 'good nursing' $[6,10,25,27]$. Reasons for promoting telecare, such as more efficiency by the need for less professional staff to care for more patients who 'manage themselves', are often seen as distant from care practice, and did not help to relieve these concerns $[3,21]$.

In this article I will take these worries seriously, and analyse what happens to them by studying telenursing within innovative telecare practices for chronic patients in the Netherlands. What kind of notions and norms of good care does telenursing bring and how do these relate to norms and notions of good nursing that were already there? What does this mean for concerns about the heart of good nursing, i.e. the relation between nurse and patients and the fear for neglect?

\section{Good Nursing in Clinical Practice}

Good nursing is obviously not a static, a-historical thing and is related to many different local developments, the introductions of new technologies, buildings, different types of patients, organisations and changing notions of what is 'good care'

\footnotetext{
${ }^{1}$ Telecare is a term that loosely refers to many different carepractices using many different devices. Telecare is s 'direct patient care, in which the recipient is at home and spatially remote from the clinician, nurse or informal carer, and in which communication media are used'. This definition is an adaptation from a recent Cochrane definition of telemedicine [4]. Telecare is discerned from 'telemedicine', which involves the communication with patients at home. In our project, we studied three classes of telecare in the Netherlands: monitoring devices, educational devices and webcam projects.

2 The conference was called 'Telecare: Dialogue and Debate-The emergence of new technologies and responsibilities for healthcare at home in Europe' and took place in Utrecht, Netherlands, 20 \& 21 September 2007. It is documented well: see http://www.csi.ensmp.fr/WebCSI/MEDUSE/, last accessed: 28 July 2008 .
} 
and 'good knowledge' for both nurses and other disciplines [6, 8, 9, 14]. In this paper, I will not depart from a theory of what good nursing is, but I will trace notions and norms of good nursing in what nurses in our study told about what they do in their practices and how they value this. The method to do this was what I would call the 'auto-ethnographic interview'. Instead of asking for opinions straight away, detailed questions were asked about daily routines, ways of working and practical matters in care. Informants were hence asked to observe their own nursing practices. In addition, we asked patients and nurses to demonstrate the telecare devices they used, and we were able to witness some training sessions where patients learned to use the equipment. We also observed the work in the call centre.

Nine specialised nurses were interviewed in depth, as well as the 33 patients. These informants were spread over five different telecare projects that involved one homecare organisation, seven hospital departments (cardiology, diabetes \& oncology), one rehabilitation clinic and a regional network of general practices. Different participants in these projects were also interviewed: other medical specialists (4), telecare managers (13), volunteers (2), technicians (3) and producers (2), some for several times.

The telecare devices I will focus on in this paper are, first, a monitoring device for heart failure patients. Patients are asked to weigh themselves and measure their blood pressure daily. The measuring devices send the numbers to a server where they are coded and may be retrieved by the nurses. Patients can keep track of their measurements by a program that can be made visible on their television. Call centre nurses monitor the development of these numbers; a sudden gain in weight may point to fluid retentions that may be, when neglected, lethal to heart failure patients. Low blood pressure may point to medication problems.

The second device monitors patients as well, but not by attached measuring devices, but by daily asking questions. To this end, a white device with a screen on which the questions appear, and four buttons to answer these, is installed in their homes. Some questions made patients observe their bodies for symptoms, others served as a way to educate patients about the particular disease they have and ways to live with it in a good way. Specialised nurses in the hospital (heart failure patients; diabetes patients; oncology patients using palliative chemotherapy), or assistants in general practices (diabetes patients) keep an eye on the answers patients give, and are warned by alarm signals if answers suggest there may e trouble and interference might be needed.

\section{Analysis}

The material was analysed by tracing norms and notions of 'good nursing' and their tensions. This makes the paper a study in empirical ethics, where good nursing is studied as it is being enacted in particular practices, in of everyday activities, objects and routines $[12,17,29]$. The attempt is hence not to judge participants in the field, but to articulate the complexities of their practices, hence allowing for a discussion as to what practices of good care might actually be best for whom.

Norms of good care are not only embedded in nursing practices, but are also scripted in telecare devices. The notion that technologies have a script is developed 
by Akrich [1] and Latour [7] Just like movies and plays, technologies can be seen as containing scripts that direct their users/players as to what characters they are, what they should do when, and how to do it well. Telecare devices bring norms to the clinic and the home that aim to direct nurses and patients to particular ways of caring. The users of the technology will, in their turn, try to make the device fit with their own plans of good use.

Elsewhere we argue to call this process the taming and unleashing of devices ánd people using them [21]. In innovative care practices, unleashed devices will work differently than anticipated during their design on the drawing board. Users will try to tame them, or maybe find themselves unleashed by finding new uses for the devices. The devices in their turn may support their user's ambitions or tame their efforts.

\section{Norms of Good Nursing}

Keeping Up the Old Standards: Translating General Norms to Individuals

What norms for good nursing does telenursing bring and how do these relate to clinical norms and notions of good nursing? The first example is from a hospital ward for heart failure patients. It shows a clash between a particular norm in clinical nursing and norms scripted in the educational telecare device. The norm the educational device tries to implement is a general one, projecting the right way of living with heart failure. Patients were asked questions about their weight, about physical activity, the use of salt, the good of eating fruits, about cholesterol, medication, sex, mood, and so on. According to the script of the protocol all heart failure patients should be careful with salt, and exercise is good for every patient. The script of the protocol was hence based on the idea that there is one good way to live with heart failure. The alarm labels signal a deviation from this general 'good lifestyle' and this is the clinical relevance the device is scripted to supply.

This general recipe of good patient care turned out to be in tension with norms of flexibility, individually tailored care and clinical relevance within clinical nursing. Here, care should be carefully tuned to the particular situation of individual patients. Signs and symptoms can only be made relevant by relating them to the specific situation of a patient. As isolated numbers or unconnected events they would be meaningless.

This became clear when we interviewed Mrs Smith, a woman of 83 years old. She did not see the sense in getting physical exercise, even though the telecare device (that patients affectionately call 'the little box') taught her that she should. When the box presented the question whether she had exercised, she answered 'no', because she wanted to be truthful. ${ }^{3}$ An alarm was send to the nurses' office, and the nurses followed it up. But when they called Mrs Smith and she explained that she did not want to do it, the nurses accepted this.

\footnotetext{
3 'Speaking the truth'is not the only way of answering. Other patients negotiated their answers with expected responses for the nurse, and their own care for the nurse.
} 
Heart failure nurse: You keep an eye on it, but when everything is stable, I do not complain about it. Some people choose to not follow some advice. One woman just says: It's all right with me, this box and all these questions, but I don't do it. I will only eat without salt for 3 days a week. And I cannot do more. And if someone manages, one way or another, and they are in a good condition, you should not make it stricter than is necessary.

Good nursing to this nurse means: flexibly deal with the whims of each patient, as long as they don't get hurt. This norm of good clinical nursing conflicted with the norms of good care scripted in the telecare device. Happily for the patients, the nurses held onto their ideas and norms of good nursing and stuck to the individualised treatment. But sadly for the nurses, this implied a more complicated dealing with the telecare device. The device kept sending alarms to the nurses, even when 'deals' with particular patients were made. This made alarms ambiguous to interpret. This could not be changed for individual patients, the nurses learnt from he technicians (say: switching off alarms for Mrs Smith not walking). In this case, the nurses worked around the norms scripted in the device. They kept up their own clinical norms of good nursing in favour of the general textbook lessons on heart failure. ${ }^{4}$

Yet this keeping up of preferred clinical norms did come at a prize for the nurses. It meant that when they knew the patients and accepted their particular ways of living, they had to ignore the alarms pointing to this 'agreed deviation' of the protocol. The alarms could not be -and were not- used at face value, but had to be interpreted against the background of the patient the alarm referred to. This ambiguity of alarms also came up when the nurses were interested in topics that did not merit attention (alarm) in general, but did so for a particular patient.

In this case, the nurses started reading all the answers and established their own criteria for judging them, calling up patients when they were in doubt. This meant an impressive multiplication of the amount of 'clinical' information they received when compared to the four times a year visits that used to be the standard. Answers came in every day, taking approximately $2 \mathrm{~min}$ per patient per day to read, not counting the follow up calls.

So there is a clash between norms (general life style rules versus tailor-made care) and a solution for saving the best option (tailor-made care) by extra work of the nurses. Different from the promise of the economising of nursing power, extra burden is put on the nurses to correct the problems the telecare device introduced. Yet, also different from the fear of the impoverishing of care for patients, patients felt very close to the nurse, because they felt they were checked everyday (see [18], and see below).

\footnotetext{
4 This reflects a difference between the tradition of 'clinical knowledge' and the tradition of 'laboratory knowledge' [26]. The clinical tradition refers to the treatment of individual patients, callibrating different variables to match their situation [13]. The laborator tradition refers to the scientific tradition that in these days would be called 'evidence based nursing', finding statistical support for the effectivity of cerntain treatments. In this article, however, we will be adressing both as clinical, because laboratory evidence comes to matter only when put to use in clinical care.
} 
The second example is about a partially successful division of labour-and normswhen call centre nurses are connected to the specialised heart failure nursing teams in the hospitals. A first division is made between the nurses seeing the patient, the hospital nurses, and those who do not, the call centre nurses. The idea that professional caregivers should see their patients is not contested, but delegated to one set of professionals, whereas the others may do their jobs using the telephone.

Heart failure nurse: You should take care when you are going to use such a [telecare device]. Maybe you should say: you should have seen the patient twice or trice, before you put him on the device. Because, yes, I don't know how to say it, but the way a patient looks has an influence on how you deal with them. It may sound strange, but it is true.

This nurse has difficulties to put it into words; it may be the 6th sense the nurse mentioned at the start of this paper that is needed to ensure good patient care. Seeing the patient face to face is pivotal for this. The cardiologist also stresses the importance of seeing the patient for diagnostic reasons.

Cardiologist: Particularly the very ill you need to see and get to know face to face. Individual circumstances make all the difference. 'Shortness of breath' may not mean much for one particular patient, but may be a very severe symptom for the next. When you see patients face to face, you can see a lot, things that will escape you, even if you have a webcam. The colour of the skin, the way someone walks towards you, a cold handshake or a pointed nose... Some things you have to really see and feel.

Again, the clinical importance of individual differences in order to make a reliable assessment of a patient's condition is stressed. Actually meeting the patient means that different variables can be taken in for diagnosis, and tests and physical examinations can be done. The clinical visit is deemed too important for good patient care to be swapped for telecare or telephone contacts. Here, in the words of the nurses and the cardiologist, good telecare depends on good clinical care: the telecare device cannot function properly without the clinical ways and routines of getting to know and caring for patients.

The call centre nurse told a different story. She told how she can do her work well without seeing the patient herself. With some reshaping and development of new skills, she claimed she could also do the job by telephone. These new skills were about turning things she would have observed when she was actually visiting a patient, into questions. Although she stressed that it was pivotal that the responsible heart failure nurse actually meets the patients, she felt confident she could do a proper nursing job with the exclusion of the visual-and also the smelly bits.

Specialised nurse in call centre: Most of the things you can find out by asking the right questions. Stuff like 'swollen ankles'. Then you ask for instance: can you still put on your shoe easily? And people tend to make things look nicer 
than they are. But by means of a social chat you will notice if people actually make it to the shops or to their family.

The nurse borrowed and directed the eyes of the patient to observe what she knew are relevant clinical signs for heart failure trouble, or patients being hindered by their symptoms. But she did more than that. She also needed stories about every day life to point and ground her 'clinical ear' and interpret the signs for their relevance. Do patients get to the shops, even if they say their ankles are ok?

Interestingly, this practice of not being able to see patients also brought out disadvantages of seeing patients. This can be seen as a cautious move towards valuing telecare norms over other clinical norms instead of pacifying conflicts.

Interviewer: How do you experience being at the computer screen instead of visiting patients at home?

Call centre nurse: That is a choice I made. I did want to do something for patients in care, but I did not particularly want to see them. The good thing with not seeing patients is that you somehow start afresh. An image can also distract. If you know what someone looks like, you can become prejudiced. There is a lot of information you do not actually need, for instance if someone is smelly, or looks unkempt. We have a fixed list to go through: meds, allergies, history. It's a fresh image.

This nurse found a way of good nursing where physical presence and 'visibility' were not prerequisites for good nursing. In defining the information she needed for taking care of people with heart failure, the call centre nurse excluded the way the patient dresses and smells as relevant signs. Good nursing here meant concentrating on the physical condition, as the monitoring device was scripted to do, and ignoring disturbing impressions.

Indeed, this is a big change from the idea of the 6th sense that may be used to spot any kind of problems. In the clinical context 'not dressing well' might indeed be a relevant pointer to problems a patient may have, especially when they used to be smart dressers before. The telecare device thus specialises the observations of the nurse (weight and blood pressure, and other heart failure symptoms are targeted; not all particulars are relevant), while at the same time intensifying these specialised observations (by measuring them daily).

The division of labour was not seamless. The nurses from the call centre were sometimes troubled by the difficult route they had to take in order to induce a small change in a patient's (often diuretic) medication. The call centre nurse had to call the responsible heart failure nurse, who in her turn may have had to talk to the cardiologist. The heart failure nurse called back the call centre nurse, who in her turn called back the patient. This 'coordination work' was felt as very elaborate. The heart failure nurses in the hospital, however, felt that their patients disappeared from their view, whereas they remained responsible for them and they had to keep the patient record for the call centre up to date. The call centre record was a double to their own administration. Particularly, the nurses saw the extra administrative work as a distraction from what they saw was their job as specialised nurses: providing good patient care. 
Oncology nurse: It's just, it is so much extra work. It's a fax to the GP, making a new file there, noting details about the patients and writing timesheets. And also your research, that again costs time! It's all really small things, but added up, it's a lot. It is all time that is not spent on your patients.

The oncology nurse did not work with a call centre. But hospital nurses who did, said they would rather have used these devices themselves, as a complement to their own clinical practice rather than doing the administrative work.

This latter remark relates directly to the notion of the heart of the nursing job mentioned at the start of this paper: the hospital nurses prefer more rather than less information about their patients. They liked the telecare devices when they would bring in more info. 'Seeing patients' became one element in patient care among many, losing its significance as a gold standard of good care in competition with other ways of checking on patients. The division of labour, however, is not complete, the (potential) conflict is unresolved. 'Seeing patients' is still seen as necessary for good practice.

\section{Substantial Changes and Improved Care}

The third example of a meeting between norms of good nursing shows how telecare is seen to improve clinical practice. Here, the standard of clinical care is abandoned as a gold standard. The project leader and the nurse in the call centre talked about what care for heart failure patients is all about.

Meeting with call centre staff: 'Time and attention is very important for these patients', says the project coordinator. 'What is heart failure? You go to the hospital, there is always limited time, and if you managed to solve one problem there, the next problem will pop up the other day. Information is not taken in all at once, or patients forget to ask the questions they wanted to ask.' The call centre nurse ads: 'What is always difficult for this group of patients, is for them to accept that they are ill. This takes a lot of time.' The project coordinator says: 'Quality of living comes first in our project, it is most important. And that quality is found in the daily hassle. And in education, self care and practical advices.'

In this quote, the call centre staff tells that telecare allows them to better attend to changing and changeable trouble in the 'daily hassle' of living with disease. By its frequent monitoring, this care practice may thus attend better to the process nature of an illness than the face to face encounter in the clinic. The situation of the patients changes over time, and so it helps that the patient is checked frequently and is at liberty to call in whenever he or she wants to discuss worries (even if only some of the patients do this). With the possibility of frequent monitoring -and calling- the possibility for a high frequency of contacts with the patient became possible and attractive.

The daily delivery of signs from and the possibility of frequent contacts with the patient brought patient and nurse closer to each other. Instead of once every 3 months, the nurses got information from their patients every day. For the educational device, even more symptoms could be monitored: 
Heart failure nurse: You get to see patients earlier, yes, you are right on top! People do not call when they get the advice to do so [shown on the box]. So you had to be lucky that they would come to the hospital when it was a bad time for them. And if they didn't, they would end up in the hospital. You cannot always prevent that, but you are much more on top of things.

Patients hardly ever called the nurse, even when the telecare device urged them to do this. But the device corrected this by sending out information that would warn the nurse that something might be wrong. When this happened, the nurse called the patient. Hence, the nurses felt they could be 'on top'. They knew something was wrong at an early stage, even when patients did not call. The continuous flow of information, independent of the patient's interpretation of the relevance of this information, became a new tool for the nurses to care for their patients in a different way: by reacting quickly when something was out of the ordinary.

For the patients this daily connection to the nurses was, however, not seen as impersonal, but induced feelings of safety and connection to the nurse.

Mr Danick: If they would take it [the telecare] away from me, it will be like taking my phone. Some of your security would disappear. Of course, you know a lot, because you have a lot of experience with your heart and with your body. But this is one step further, so to speak. It feels safer. The thought that there are people out there who check you puts you at ease.

And Mrs Toulmin:

When there are new questions to answer, the light flashes. 'It's Tania's [nurse] wink', we always say. 'Tania is winking at us'.

The patients experienced the telecare as a daily check by the nurses, bringing the nurses close to them. The nurses also experience closeness, but relate this, not to the information from the telecare device (which was often ambiguous), but to the use of the telephone.

Heart failure nurse: What we notice, particularly in the beginning, is that patients give answers the caregivers need to respond to. So the contact over the phone with people newly connected is rather intense. And, one way or another, you notice that you become more familiar with these people, even on the telephone. You get a good contact. Because they start trusting you: 'Hey, they will call me if there is something.' To them, that's a revelation, really.

But was this 'merely' an improvement or intensification of the former ways of nursing? I would suggest that it was a rather big change in the relation between patients and nurse as well. The nurse no longer reacted to the questions and problems the patient put forward or problems they discovered in the clinical encounter four times a year (or more often when the patient called in). In the case of telecare, the nurse cared by exercising professional control. The ideal of leaving the initiative to ask for help with the patient, and hence not medicalise them unnecessarily, intrude on their private sphere unnecessarily, or make them less 
responsible for their own care, was backgrounded. Prevention, professional expertise and the feeling of safety of the patients were foregrounded.

So what happened here was that, with the changing of the practice, new norms and goals became important or gained ground: frequent contact to deal with day to day changes, prevention of exacerbations, professional responsibility, information that is not dependent on patient interpretation and initiative. This feeds in rather well to the nurses' fear for negligence and the urge to spot problems with which this paper set off. Ironically, the nurses may have found their mechanical sixth sense in the practice they feared would take it away: telecare practice. The patient may find him or herself warmly wrapped up in a blanket of professional care, maintaining good relations by sending out 'information' that is checked.

\section{New Tasks, New Goals}

So far, a clear relation between telecare and the treatment of patients was kept together. In the fourth example this link was broken. Telecare unleashed new tasks, goals and norms for the nurses. The educational device made the nurses learn new things about the patients, different from what they would learn in the face to face encounter.

Heart failure nurse: We were really flabbergasted about what answers people gave. They gave answers, that made us think: 'What is this? Doesn't he know that?!' All of a sudden you get an enormous amount of information from a patient, and you do not get this information in the half an hour face to face contact. So the box is a very good way to get to know what the missing bits are for a patient.

The device thus pointed the nurses to things that cannot be dealt with in the half an hour consultation every 3 months. These 'things' took a specific shape: they were facts about the disease and life style rules that patients did or did not know. And these could have been many. This made the nurses think about what is important to learn from the patients. New topics became a matter of concern. These were problems the device identified in the variety of questions that were posed throughout the months. Examples that particularly worried the nurses were mood- or sex problems. These might come up during the face to face consultation, but could also remain invisible if the patients did not report them. But even if not reported, these may be bothering them.

Seeing the answers from many patients made the nurses wonder: what do we know about mood and sexual problems for people with heart failure? If these problems turn out to be concerning many patients, how can we learn if this is the case and maybe add something to the care we deliver in order to change that?

Nurse: If 80 out of 100 patients give the wrong answer to a certain question, you should look at yourself. Not at the patient, but at the way you explain things. So it's a way of controlling yourself, to see if you transport information in the right way. And how can we do that in a better way. 
So the use of the device was shifted away from direct treatment and became an instrument to study the care practice of the nurses. Rather than 'hands on' -or 'phones on'- clinicians, the nurses became researchers of their own practice. The object of their research was also different from the object of face to face clinical practice. It was not the individual patients, but the group of patients with specific characteristics.

In order to fit the new goal, the singular observations over the telecare device had to be re-organised. Devoid of the context in which they were produced, it was not always clear what the information meant. Was a particular patient just reporting a blue day? Or did the blue day point to a depression that had to be treated? With all these questions 'out of context', it was not clear how stable one observation was. For patient care, the individual context of the patient would have to be made available. For research practices, a different mode of interpreting individual answers was thought of. The nurses wanted statistics on the group of patients to interpret the information. By gathering numbers over the group of patients, they intended to quantify the information in order to establish if certain problems where typical for their group of patients.

Sadly, however, at this point the device disappointed the need it helped into being: with this script, it was not possible to make statistics over the group of patients. The only possible graphs were those summarising measurements for individual patients. This made the nurses puzzle about different ways of getting the information they needed, e.g. by sending out questionnaires over the device to asses depression. Again, the nurses had to do the work for realising what they thought was important for good patient care, even if the device itself had brought this desire into being. But this time, they formulated different goals that were unleashed by the script of the device and were brought out by the nurses' statistical ways of reasoning.

This shift to practical quantitative research meant a shift towards embedding some form of local epidemiological research in clinical practice. To the nurses, this was a valuable option that was not intended, but still unleashed by the use of the telecare device. However, instead of economising on nursing labour, as wished for in telecare promotion, this local research work again served the nurses with extra rather than less work, uncovering more problems rather than keeping these away from health care. Yet this appeals to a nursing heart that fears to miss out on patient trouble.

\section{Concluding Discussion}

The analysis demonstrated particular shifts in clinical practice and norms and notions of good nursing, depending on the way particular telecare devices were scripted and put to use. These analyses may help reflect upon the fears for the possibility to take good care of patients, keep them from harm and develop good relationships. What happened to these concerns?

First, the nurses had to work harder, because they accommodated many changes that came along with telenursing. The nurses 'worked around' some of these 
changes, in order to keep up what they found important in their care. Often, this 'working around' had to do with the 'correction' of the information the devices-andpatients generated. This information had to be related to the individual context of the patients in order be made clinically relevant. Even the most exact measurements only get their clinical significance when related to the situation of an individual. A sign that may cause alarm for one patient may not be so bad for another. The daily monitoring meant many signs were steadily coming in. Added to this was the extra administrative work, so with the implementation of telecare, more rather than less work is to be expected for the nurses using these devices.

In the cases studied, the nurses stuck to their familiar clinical styles of nursing in difficult circumstances. Telecare was successful because the nurses took care of the link to clinical practice. They did this in face-to-face encounters, but also by telephone. The telephone deserves a much more central place in discussions about telecare, because it is crucial for making the other/new devices' information clinically relevant. In how far the phone contacts could replace face-to-face encounters, was a discussion that was neutralized by the professionals. Completely swapping telecare for face to face contact was not deemed feasible of desirable, even if 'seeing patients' was no longer the core business of all professional nurses involved, and was seen to have it's problematic sides, too. It is not clear what will happen to face-to-face contacts in the future when telecare devices are used more often. The professional value attached to it, however, works as a safeguard here, as well as the need to interpret information collected by the devices-and-patients.

However, it became clear that the difference between 'seeing patients' face to face or monitoring them with the telecare device and the telephone was not a mere difference between more or less senses used. The nurse's eyes could be swapped for her ears, turning the patients into observers of symptoms. New strategies were designed to compensate for absent senses. In many ways telcare was more intense and frequent than face to face contact. This was also analysed in webcam use: by it's location in the home, the existing relation between participants and the focussing on the image of the face of the other, made the conversation even closer than real encounters [19, 23].

The heart of good nursing may have shrunk when it became clear that not 'everything' could be seen. Yet the telecare devices allowed for much more frequent consultations and checks and a closer guarding of the patients' condition by attending to the process of being ill. Rather than putting nurses and patients at a distance, all examples pointed in the opposite direction: it made patients and nurses (feel) closer to one another. The nurses' 6th sense to spot problems was turned into daily monitoring of information produced -but not interpreted- by the patients, who were intensively followed up with phone calls. With the creative idea of putting telecare devices to work as local research instruments, even more problems the patients might have may be detected. Telecare turned out to be more, rather than less intensive. Instead of 'care at a distance', it became 'care even closer'.

So, one should not be blinded by quantity alone. The intensification of care also changed the kind of information exchanged: rather than a physically present patient with many or little stories, there were blood pressure measurements and answers to questions. The telecare devices intensified contacts (by their frequency), and, 
depending on the device, specified the contacts by making some things relevant rather than others, and multiplying relevant variables by asking different sorts of questions. There is a difference between learning things from how a person looks and receiving signs of blood pressure in between consultations. The feeling of safety and security the patients experienced, may not always have been realistic. They were still people with chronic and potentially fatal diseases and telecare will not prevent every crisis.

Hence, the value of 'feeling safe' as it is related to 'spotting any problem' deserves more serious reflection. When either way of spotting problems, be it face to face, by telephone or by monitoring, reveals particular problems, this leaves the question open what problems should be picked up in order for care to be good. And how far should professional surveillance go? Should professional nurses try to spot 'any problem', even if this means they are taking over much of the responsibility of the patients? It turned out that the patients in the practices studied became passive rather than more responsible for their own condition and care (see also [20, 24]). Because the nurses took over the surveillance of their condition, patients expected and waited for the nurses to call them when something was wrong. One could argue about the desirability of this passivity, even if the patients were very happy with it.

These are ethical questions, but they are also pragmatic questions. Being responsible for 'any problem' may also make the nursing heart fail under the burden. Rather than relieving their duties, telecare was rather seen to extend nursing tasks (see also: [22]).

Acknowledgments This paper is written as part of the project 'Care from a distance. A normative investigation into telecare.' In which I work with Dick Willems (AMC) en Maartje Schermer (ErasmusMC). NWO 'Ethiek, Onderzoek en Bestuur' [Ethics, research and policy] finances the research. I am grateful to Amâde M'Charek and Dick Willems for their comments on earlier versions of this paper, to the nurses, patients and others informants for this research, and to Annemarie Mol and Ingunn Moser for intellectual company in our work on care.

Open Access This article is distributed under the terms of the Creative Commons Attribution Noncommercial License which permits any noncommercial use, distribution, and reproduction in any medium, provided the original author(s) and source are credited.

\section{References}

1. Akrich, M. (1992) The de-scription of technical objects. In W. E. Bijker \& J. Law (Eds.), Shaping technology/building society. Studies in sociotechnical change (pp. 205-224). Cambridge (MS), London (GB): The MIT Press.

2. Bauer, K. (2004). Cyber medicine and the moral integrity of the physician-patient relationship. Ethics and Information Technology, 6, 83-91.

3. Boonstra, A., Broekhuis, M., van Offenbeek M., Westerman, W., Wijngaard, J., \& Wortman, H. (2008) Kijken op afstand. Op zoek naar de effectiviteit en efficiency van Koala telecare en telecure. Publieksversie van het eindrapport RuG/RHO: 'Kijken op afstand, een leerzaam alternatief' Groningen: RuG/RHO. http://www.zorginnovatieforum.nl/projecten/ZoA/Koala\%20eindrapport.pdf, last consulted 29 oktober 2009.

4. Currell, R., Urquhart, C., Wainwright, P., et al. (2000). Telemedicine versus face tot face patient care: Effects on professional practice and health care outcomes. Chichester: John Wiley \& Sons, The Cochrane Library. 
5. Gammon, D., Sörlie, T., Bergvik, S., \& Sörensen Höifödt, T. (1998). Psychotherapy supervision conducted via videoconferencing: A qualitative study of users' experiences. Nordic Journal of Psychiatry, 52, 411-421.

6. Greatbatch, D., Hanlon, G., Goode, J., O'Cathain, A., Strangleman, D., \& Luff, D. (2005). Telephone triage, expert systems and clinical expertise. Sociology of Health \& Illness, 27(6), 802-830.

7. Latour, B. (1992). Where are the missing masses? The sociology of a few mundane artifacts. In W. E. Bijker \& J. Law (Eds.), Shaping technology/building society. Studies in sociotechnical change (pp. 225-258). Cambridge (MS), London (GB): The MIT Press.

8. Lehoux, P., Sicotte, C., Denis, J. L., Berg, M., \& Lacroix, A. (2002). The theory of use behind telemedicine: How compatible with physicians' clinical routines? Social Science and Medicine, 54, 889-904.

9. May, C., Gask, L., Atkinson, T., Ellis, N., Mair, F., \& Esmail, A. (2001). Resisting and promoting new technologies in clinical practice: The case of telepsychiatry. Social Science and Medicine, 52(12), 1889-1901.

10. Miller, J. F. (2006). Opportunities and obstacles for good work in nursing. Nursing Ethics, 13(5), 471-487.

11. Milligan, C., Roberts, C., Mort, M., \& Moser, I. (2006) MEDUSE Policy Paper: the Emergence of New Technologies and Responsibilities for Health Care at Home in Europe. www.csi.ensmp. fr/WebCSI/MEDUSE/.

12. Mol, A. (2002). The body multiple. Ontology in medical practice. Durham and London: Duke University Press.

13. Mol, A. (2008). The logic of care. London: Routledge.

14. Nicolini, D. (2006). The work to make telemedicine work: A social and articulative view. Social Science and Medicine, 62, 2754-2767.

15. Norman, S. (2006). The use of telemedicine in psych. Journal of psychiatric and mental health nursing, 13, 771-777.

16. Onor, M. L., \& Misan, S. (2005). The clinical interview and the doctor-patient relationship in telemedicine. Telemedicine and e-health, 11, 102-105.

17. Pols, J. (2008). Which empirical research, whose ethics? Articulating ideals in long-term mental health care. In Widdershoven, G., Hope, T., Van der Scheer, L., \& McMillan, J. (Eds.), Empirical ethics in psychiatry (pp. 51-68). Oxford: Oxford University Press.

18. Pols, J. (2009). Telecare: What patients care about. In Mol, A., Moser, I., \& Pols, J. (Eds.), Care in practice. Bielefeld: Transcript Verlag (forthcoming-a).

19. Pols, J. (2009). Wonderful webcams. About active gazes and invisible technologies. Science, Technology \& Human Values (forthcoming,-b).

20. Pols, J., \& Moser, I. (2009). Cold technologies versus warm care? On affective and social relations with and through care technologies, ALTER. European Journal of Disability Research, 3(2009), 159-178.

21. Pols, J., \& Willems, D. (2009). Evaluation without promises. Unleashing and taming the telekit (forthcoming).

22. Pols, J., Schermer, M., \& Willems, D. (2008). Telezorgvisie Essay over ontwikkelingen en beloften van telezorg in de Nederlandse gezondheidszorg. (Telecare visions. Essay on the developments and promises of telecare in Dutch health care). Amsterdam: Academic Medical Centre.

23. Sävenstedt, S., Zingmark, K., Hydén, L. C., \& Brulin, C. (2005). Establishing joint attention in remote talks with the elderly about health: A study of nurses'conversation with elderly persons in teleconsultations. Scandinavian Journal of the Caring Sciences, 19, 317-324.

24. Schermer, M. (2009). Telecare and self-management: Opportunity to change the paradigm? Journal of Medical Ethics, 35, 688-691.

25. Smith, K. V., \& Godfrey, N. S. (2002). Being a good nurse and doing the right thing: A qualitative study. Nursing Ethics, 9(3), 301-312.

26. Struhkamp, R., Mol, A., \& Swierstra, T. (2009). Dealing with in/dependence. Doctoring in physical rehabilitation practice. Science Technology Human Values, 34, 55-76.

27. Tuckett, A. G. (2002). An ethic of the fitting: A conceptual framework for nursing practice. Nursing Inquiry, 5(4), 220-227.

28. Van Kammen, J. (red). (2000). Zorgtechnologie, kansen voor innovatie en gebruik. (Care technology, chances for innnovation and use) Den Haag: Stichting Toekomstbeeld der Techniek (STT), 2002. 
29. Willems, D. L. (2003). Een wereld van verschil. Pluralisme in de medische ethiek. (A world of difference. Pluralism in medical ethics). Amsterdam: AU Press.

30. Willems, D. (2004). Geavanceerde thuiszorgtechnologie: morele vragen bij een ethisch ideaal. (Advanced homecare technology: Moral questions with an ethical ideal.) In Gezondheidsraad (Ed.), Signalering Ethiek en Gezondheid. Den Haag: Gezondheidsraad. 